\title{
PENGARUH KEPUASAN KERJA TERHADAP ORGANIZATIONAL CITIZENSHIP BEHAVIOR (OCB) KOMITMEN ORGANISASI SEBAGAI VARIABEL INTERVENING (STUDI KASUS PADA PT CITAYASAH PERDANA)
}

\author{
Khasbulloh Huda \\ Universitas Mayjen Sungkono Mojokerto \\ Email: huda.khasbulloh@yahoo.com
}

\begin{abstract}
Organizations generally believe that excellence must be maintained for performance, as performance essentially affects teamwork or group work and ultimately affects overall employee performance. Therefore, to pursue and improve the required performance, job satisfaction, commitment and individual sportive behavior. This study examines how much influence the job satisfaction, organizational commitment and Organization Citizenship Behavior (OCB) for employee performance.

This study aims to know and analyze How the Influence of Job Satisfaction, Organizational Commitment, to Organization Citizenship Behavior (OCB) employees. Technique Determination of the sample is done through purposive (purposive sampling), using sampling rendom samples, by distributing questionnaires to technical service personnel of PT. Citayasa Perdana. This research is designed as an explanatory research model, that is to explain how the influence of job satisfaction, commitment, in improving Organization Citizenship Behavior (OCB) employees. Therefore, after considering the objectives and proposed hepotesis problem and the available data, in this research digunalan 2 kinds of analysis, namely: 1). Descriptive analysis, and 2). Path Analysis (pats analysis). The results of this study indicate that Job Satisfaction affects the commitment of oranisasi, the satisfaction of the influence of Organizational Behavior Organizational Behavior (OCB) and Organizational Commitment affect the Organization Citizenship Behavior (OCB), and Job Satisfaction also affect the Organization Citizenship Behavior (OCB) through Commitment Organization.
\end{abstract}

\section{ABSTRAK}

Organisasi umumnya percaya bahwa keunggulan harus tetap dipertahankan demi meningkatnya kinerja, karena kinerja pada dasarnya mempengaruhi kerja tim atau kerja kelompok dan pada akhirnya mempengaruhi kinerja pegawai secara keseluruhan. Oleh karena itu, untuk mengejar dan meningkatkan kinerja diperlukan, kepuasan kerja, komitmen dan perilaku sportif individu. Penelitian ini menguji seberapa besar pengaruh kepuasan kerja, komitmen organisasi dan Organization Citizenship Behavior (OCB) untuk kinerja pegawai.

Penelitian ini bertujuan untuk mengetahui dan menganalisis Bagaimana Pengaruh Kepuasan Kerja, Komitmen Organisasi, terhadap Organization Citizenship Behavior (OCB) pegawai. Teknik Penentuan sampel dilakukan melalui purposif (purposive sampling), mengunakan sampel rendom sampling, dengan membagikan kuesioner pada petugas pelayanan teknik PT. Citayasah Perdana Mojokerto. Penelitian ini dirancang sebagai model penelitian eksplanatori, yaitu untuk menjelaskan bagaimana pengaruh kepuasan kerja, komitmen, dalam meningkatkan Organization Citizenship Behavior (OCB) pegawai. Untuk itu setelah mempertimbangan permasalahan tujuan dan hepotesis yang diajukan serta data yang tersedia, maka dalam penelitian ini digunalan 2 macam analisis, yaitu: 1). Analisis deskriptif, dan 2). Analisis Jalur ( pats analysis ). Hasil penelitian ini menunjukan bahwa Kepuasan Kerja mempengaruhi terhadap komitmen oranisasi, kepuasan kejra mempengaruhi Organization Citizenship Behavior (OCB) dan Komitmen Organisasi mempengaruhi terhadap 
Organization Citizenship Behavior (OCB), serta Kepuasan Kerja juga mempengaruhi terhadap Organization Citizenship Behavior (OCB) melalui Komitmen Orgnaisasi.

\section{Kata kunci : kepuasan kerja, komitmen organisasi, Organization Citizenship Behavior (OCB)}

\section{PENDAHULUAN}

Pendidikan merupakan kebutuhan yang sangat pokok dan mendasar bagi setiap orang sebab dengan pendidikanlah kemajuan di dunia ini dapat kita saksikan. Manusia merasakan manfaat dari berlangsungnya pendidikan. Berbagai lembaga pendidikan berhasil melahirkan dan mencetak para ilmuwan dan sarjana yang mampu menemukan dan menciptakan hal baru yang sangat dibutuhkan untuk keberlangsungan hidup manusia. Pendidikan pada dasarnya bukan hanya sekedar transfer pengetahuan tapi lebih dari itu adalah proses membangun pemahaman, pola pikir dan juga perilaku peserta didik sehingga untuk mencapai hasil pendidikan yang optimal dibutuhkan waktu yang lama, serta pendidik yang memiliki komitmen dan dedikasi tinggi yang terkadang juga tidak seimbang dengan income yang didapatkan, oleh sebab itu pendidik khususnya di Indonesia seringkali diidentifikasi sebagai pahlawan tanpa tanda jasa.

Penelitian ini dilakukan pada PT. Citayasah Perdana sebagai pelaksana pengerjaan kebutuhan energi listrik di zaman modern seperti ini cukup tinggi, dengan tekhnologi yang semakin canggih dan hampir semuanya memakai energi listrik. Dengan kebutuhan pelanggan akan energi listrik tersebut PT. Citayasah Perdana terus berusaha menjadi perusahaan vendor yang kualitas dalam menjalankan tugas dan tanggung jawabnya.

Kepuasan kerja dan Komitmen merupakan dua faktor yang dapat meningkatkan Organizational Citizenship Behavior (OCB). Ketika karyawan merasakan kepuasan terhadap pekerjaan yang dilakukannya, maka karyawan tersebut akan bekerja secara maksimal dalam menyelesaikan pekerjaannya, bahkan melakukan beberapa hal yang mungkin di luar tugasnya Organizational Citizenship Behavior (OCB). Dan kepuasan itu timbul dari lingkungan kerja perusahaan yang dapat dikatakan kondusif yang mendukung karyawan dalam menyelesaikan pekerjaannya. Begitu juga dengan ketika seseorang mempunyai komitmen yang tinggi terhadap organisasinya, maka orang tersebut akan melakukan apapun untuk memajukan perusahaannya karena keyakinannya terhadap organisasinya.

PT. Citayasah Perdana mempunyai komitmen sebagai perusahaan Vendor yang mempunyai Integritas tinggih perusahaan vendor yang berintegritas, Bekerja Dengan Jujur Dalam Menjalankan Tugas dan Tanggung Jawab mengedepankan Pelayanan" Komitmen 
juga berisi tentang bagaimana karyawan harus dapat menciptakan lingkungan kerja yang nyaman. Karena kondisi kerja yang nyaman juga akan mendorong karyawan melakukan tugasnya dengan baik. Sehingga tujuan maupun misi perusahaan akan tercapai dan kebutuhan pelanggan akan terpenuhi.

Akan tetapi masih ada beberapa dari pegawai dengan tingkat komitmen yang rendah. Dapat dikatakan rendah karena ada beberapa pegawai yang tidak memperdulikan atau menganggap sepele komitmen tersebut dilihat dari keadaan ruang kerja dengan dokumen-dokumen yang tidak tertata rapi di rak yang telah disediakan, meletakkan barang yang bukan pada tempatnya. PT. Citayasah Perdana adalah Perusahaan vendor (rekanan) yang menyediakan tenaga tenaga yang menjalankan pekerjaan lapangan di lingkungan PT. PLN dengan tujuan melayani gangguan kelistrikan pada masyarakat. Untuk menghadapi era globalisasi yang ketat akan persaingan, setiap perusahaan dituntut untuk meningkatkan kinerja karyawan maupun OCB karyawan agar dapat mencapai tujuan perusahaan.).

Berdasarkan latar belakang yang telah diuraikan penelitian ini diberi judul " Pengaruh Kepuasan Kerja Terhadap Organizational Citizenship Behavior (OCB). Dengan Komitmen sebagai
Variabel Intervening (Studi Kasus Pada PT. Citayasah Perdana)."

\section{RUMUSAN MASALAH}

Berdasarkan latar belakang permasalahan di atas dapat disimpulkan perumusan masalah sebagai berikut :

1. Apakah kepuasan kerja berpengaruh terhadap Komitmen di PT. Citayasah Perdana?

2. Apakah kepuasan kerja berpengaruh terhadap Organizational Citizenship Behavior (OCB) di PT. Citayasah Perdana?

3. Apakah komitmen organisasi berpengaruh terhadap Organizational Citizenship Behavior (OCB) di PT. Citayasah Perdana?

4. Apakah kepuasan kerja berpengaruh terhadap Organizational Citizenship Behavior (OCB) melalui Komitmen di PT. Citayasah Perdana ?

\section{Tujuan Penelitian}

Berdasarkan pada latar belakang dan rumusan masalah yang di kemukakan sebelumnya maka penelitian ini bertujuan untuk :

1. Untuk menganalisis pengaruh Kepuasan kerja terhadap Komitmen di PT. Citayasa Perdana.

2. Untuk menganalisis pengaruh Kepuasan kerja terhadap Organizational Citizenship Behavior (OCB) di PT. Citayasah Perdana. 
3. Untuk menganalisis pengaruh komitmen organisasi terhadap Organizational Citizenship Behavior (OCB) di PT. Citayasah Perdana.

4. Untuk menganalisis pengaruh kepuasan kerja terhadap Organizational Citizenship Behavior (OCB) melalui Komitmen di PT. Citayasah Perdana.

\section{METODE PENELITIAN}

\section{Jenis Penelitian}

Sesuai dengan tujuannya, penelitian ini dirancang sebagai model penelitian eksplanatori, yaitu untuk menjelaskan bagaimana pengaruh kepuasan kerja dan komitmen, dalam meningkatkan Organizational Citizenship Behavior (OCB).

Untuk mengungkap permasalahanpermasalahannya, penelitian ini dirancang sebagai penelitian orientasi dan aksi. Penelitian dengan rancangan orientasi dan aksi memberi peluang untuk mengembangkan solusi yang bisa menyarankan adanya perubahan. ( Babbie, 1986: 79 ). Berbeda dengan penelitian karakteristik yang pada dasarnya variabelvariabel karakteristik merupakan variabel statis yang tidak mungkin diubah.

\section{Tempat dan Waktu Penelitian}

Lokasi penelitian ini dilaksanakan pada karyawan PT. Citayasas Perdana yang bertugas dalam lingkungan PT. PLN Distribusi Jawa Timur Area Pelayanan Jaringan (APJ) Mojokerto yang meliputi :
Rayon Mojokerto, Rayon Pacet, Rayon Ngoro, Rayon Jombang, Rayon Ploso, Rayon Kertosono, Rayon Warujayeng, Dan Royon Nganjuk.. Alasan dilakukan penelitian tersebut dikarenakan PT. Citayasah Perdana merupakan pemenang pelaksanaan kerja pada PLN Distribusi Jawa Timur Area Pelayanan Jaringan (APJ) Mojokerto merupakan salah satu faktor yang paling utama kebutuhan masyarakat dalam bentuk energi, bahkan dalam perekonomian maupun instansi-instansi pemerintahan serta kebutuhan perusahaan sebagai satu-satunya perusahaan pemasok energi listrik. Sehingga menjadi pusat perhatian masyarakat jika terjadinya pemadaman listrik. Terkadang masyarakat juga mengelukan seringnya padam listrik dan penanganan yang cukup lama.

\section{Teknik Pengambilan Sampel}

Penentuan sampel dalam penelitian ini menggunakan kombinasi dari beberapa metode atau teknik pengambilan sampel.( Sugiyono, 2006:89 ). Penentuan sampel dilakukan melalui purposif (purposive sampling). Secara purposif, pengambilan sampel harus menjaring 2 sifat atau kriteria yang diminta dan sesuai dengan maksud dan tujuan dalam penelitian. Kriteriakriteria yang dimaksud tersebut antara lain:

1. Karyawan yang berstatus sebagai petugas pelayanan teknik

2. Petugas pelayanan teknik yang memiliki masa kerja lebih dari 1 tahun. 
Untuk menentukan berapa sampel yang dibutuhkan, maka digunakan rumus Slovin (Husein Umar,2003:120) yaitu sebagai berikut :

Perhitungan sampel :

$$
\begin{aligned}
& \mathrm{n}=\frac{263}{1+263(0,05)^{2}} \\
& \mathrm{n}=158,476 \approx 158
\end{aligned}
$$

Sampel yang dipilih dari populasi dianggap dapat mewakili keberadaan populasi yaitu pegawai PT. Citayasah Perdana. Hasil perhitungan diperoleh sampel sebenyak 158 responden yang selanjutnya diadakan suatu survei dengan menyebarkan daftar pertanyaan.

\section{Teknik Pengukuran Variabel}

1. Uji validitas ini dimaksudkan untuk menguji seberapa baik instrumen penelitian mengukur konsep yang seharusnya diukur. Untuk mengetahui apakah item-item pertanyaan yang tersaji dalam kuesionar benar-benar mempu mengungkapkan dengan pasti tentang apa yang akan diteliti. Caranya yaitu dengan analisis item dimana setiap nilai yang ada pada setiap butir pertanyaan dikorelasikan dengan nilai total seluruh butir pertanyaan.

2. Uji reliabilitas ini merupakan bentuk uji kualitas data (kehandalan) yang menunjukkan stabilitas dan konsistensi dari instrumen untuk mengukur konstruk (variabel), Sugiyono (2008). Suatu kuisioner dikatakan reliabel jika didapatkan jawaban seseorang terhadap pertanyaan adalah konsisten atau stabil apabila digunakan berulang kali pada waktu yang berbeda, atau dari waktu ke waktu. Untuk mengetahui apakah alat ukur reliabel atau tidak, maka akan diuji dengan menggunakan metode Alpha Cronbach.

3. Analisis Statistik Inferensial yaitu suatu analisis yang dilakukan untuk menguji hipotesis penelitian yang telah di buat di mana pada penelitian ini digunakan metode analisis jalur (path analysis) yang sebelumnya dilakukan model pengukuran ditujukan untuk mengkonfirmasi sebuah dimensi atau faktor berdasarkan variabel melalui teknik confirmatory factor analysis (CFA).

\section{HASIL dan PEMBAHASAN}

Penelitian ini menggunakan teknik analisis data regresi berganda. Analisis regresi digunakan untuk mengetahui ada tidaknya pengaruh fasilitas perpustakaan dan minat baca terhadap peningkatan prestasi siswa. Berikut adalah hasil perhitungan dengan program SPSS versi IMB 20 dari input data yang telah dimasukkan diperoleh hasil sebagai berikut:

\section{Uji Validitas}

Uji validitas bertujuan untuk mengetahui bahwa item pernyataan dengan variabel-variabel adalah valid, dimana 
Validitas instrument dinilai berdasarkan standar signifikan korelasi<0,05.

\begin{tabular}{|l|l|l|l|}
\hline Variabel & Indikator & signifikasi & $\begin{array}{l}\text { Hasil } \\
\text { uji }\end{array}$ \\
\hline Kepuasan & $\mathrm{X} 1.1$ & 0.000 & Valid \\
kerja & $\mathrm{X} 1.2$ & 0.000 & Valid \\
& $\mathrm{X} 1.3$ & 0.000 & Valid \\
& $\mathrm{X} 1.4$ & 0.000 & Valid \\
\hline Komitmen & $\mathrm{Y} 1.1$ & 0.000 & Valid \\
& $\mathrm{Y} 1.2$ & 0.000 & Valid \\
& $\mathrm{Y} 1.3$ & 0.000 & Valid \\
& $\mathrm{Y} 1.4$ & 0.000 & Valid \\
& $\mathrm{Y} 1.5$ & 0.000 & Valid \\
& $\mathrm{Y} 1.6$ & 0.000 & Valid \\
\hline Organizational & $\mathrm{Y} 2.1$ & 0.000 & Valid \\
Citizenship & $\mathrm{Y} 2.2$ & 0.000 & Valid \\
Behavior & $\mathrm{Y} 2.3$ & 0.000 & Vakid \\
(OCB) & Y2.4 & 0.000 & Valid \\
& Y2.5 & 0.000 & Valid \\
\hline
\end{tabular}

Berdasarkan tabel diatas maka dapat disimpulkan semua variabel valid,hal ini dapat dibuktikan dengan nilai $\operatorname{Sig}<\alpha(5 \%)$ atau pada tinggakt kepercayaan $95 \%$.

\section{Uji Reliabilitas}

Uji Reliabilitas diukur dengan metode alfa cronbach, adapun kriteria pengujiannya adalah apabila nilai reliabilitas instrumen diatas 0,06 atau $60 \%$, maka data tersebut dikatakan realiabel.

\begin{tabular}{|l|l|l|}
\hline Variabel & alfa cronbach & Hasil uji \\
\hline Kepuasan kerja & 0,684 & Reliabel \\
\hline Komitmen & 0,618 & Reliabel \\
\hline OCB & 0,731 & Reliabel \\
\hline
\end{tabular}

Berdasarkan table di atas, dimana variabel kepuaan kerja (X) memiliki koefesien sebesar 0.648, variabel komitmen ( $\left.\mathrm{Y}_{1}\right)$ memeliki koefesien sebesar 0.615, dan variabel Organizational Citizenship Behavior (OCB) $\left(\mathrm{Y}_{2}\right)$ memeliki koefesien sebesar 0.731, maka dapat diambil kesimpulan bahwa semua variabel dalam penelitian ini adalah reliable, hal ini dibuktikan Suatu instrumen tersebut dikatakan valid (reliable) apabila memiliki cronbach alpha lebih dari 0,60 atau $60 \%$.

\section{Analisis Faktor Konfirmatori \\ (confirmatory faktor analysis)}

Teknik confirmatory factor analysis (CFA) ditujukan untuk mengestimasi measurement model, menguji unidimensionalitas dari konstruk-konstruk eksogen dan endogen. Metode statistik yang digunakan untuk menguji validitas konstruk dari analisis faktor adalah dengan melihat korelasi KMO (Kaiser-MeyerOlkin) atau Bartlett's test.

\section{Nilai Validitas Konstruk}

\begin{tabular}{|l|l|}
\hline Nilai Validtas & Cut-off Value \\
\hline KMO (Kaiser Mayer Olkin) & $>0,50$ \\
\hline X2 (Chi Square) & Diharapkan besar \\
\hline Significance Probability & $<0,05$ \\
\hline Eigen value & $>1,00$ \\
\hline Varians Kumulatif & $>60$ persen \\
\hline Anti Image & $>0,50$ \\
\hline \multicolumn{2}{|c|}{ Berdasarkan hasil analisis faktor }
\end{tabular}

konfirmatori yang disajikan pada tabel seperti berikut.

\begin{tabular}{|l|l|c|}
\hline Nilai Validtas & $\begin{array}{l}\text { Cut-off } \\
\text { Value }\end{array}$ & Hasil \\
\hline $\begin{array}{l}\text { KMO (Kaiser } \\
\text { Mayer Olkin) }\end{array}$ & $>0,50$ & 0,617 \\
\hline X2 (Chi Square) & $\begin{array}{l}\text { Diharapkan } \\
\text { besar }\end{array}$ & 264,439 \\
\hline $\begin{array}{l}\text { Significance } \\
\text { Probability }\end{array}$ & $<0,05$ & 0,000 \\
\hline Eigen value & $>1,00$ & 2,271 \\
\hline Varians Kumulatif & $>60$ persen & 75,701 \\
\hline
\end{tabular}

konfirmatori yang disajikan pada tabel seperti berikut. Berdasarkan hasil diatas menunjukkan bahwa KMO sebesar 0,617 lebih besar dari 0,5 dengan chi square 264,439 dan signifikan probability $0,000<$ 
0,000 maka analisis faktor ini bisa digunakan. Disamping itu, faktor bermakna dari eigen value sebesar 2,271 > 1,00 dan varian kumulatif lebih besar dari 60 persen yaitu sebesar 75,710 persen.

\begin{tabular}{|c|c|c|}
\hline Variabel & MSA & Keterangan \\
\hline Kepuasan kerja & 0,664 & Valid \\
\hline Komitmen & 0,641 & Valid \\
\hline OCB & 0,573 & Valid \\
\hline
\end{tabular}

Berdasarkan Tabel diatas menunjukkan bahwa MSA seluruh variabel faktor memiliki nilai lebih besar dari 0,50 dan semua syarat terpenuhi maka dapat disimpulkan bahwa variabel tersebut valid.

\section{Analisis jalur (path analysis)}

Pengujian data dilakukan dengan analisis jalur (path analysis), yaitu menguji pola hubungan yang mengungkap pengaruh variabel dengan atau seperangkat veriabel terhadap variabel lainnya, baik pengaruh langsung maupun pengaruh tidak langsung.

Didalam analisis jalur adalah pendugaan parameter atau perhitungan koefisien path. Untuk pendugaan parameter dilakukan dengan analisis regresi melalui software SPSS IMB 20. Hasil dari analisis substruktur persamaan disjikan pada lampiran dan dilaporkan sebagai berikut.

Summary dan Koefisien Jalur 1

\begin{tabular}{|l|l|l|l|}
\hline Variabel & $\begin{array}{l}\text { Koefesien } \\
\text { Reliabilitas }\end{array}$ & $\begin{array}{l}\mathrm{T} \\
\text { Hitung }\end{array}$ & Sig \\
\hline $\begin{array}{l}\text { Kepuasan } \\
\text { kerja }\end{array}$ & 0.467 & 7.155 & 0.000 \\
\hline $\begin{array}{l}\text { Constanta } \\
\text { Koefesien Determinasi }\end{array}$ & 2.198 \\
$\left(\mathrm{R}^{2}\right)$ & 0.213 \\
$\mathrm{~F}_{\text {Hitung }}$ & 51.193 \\
$\alpha$ & 0.248 \\
\hline
\end{tabular}

Berdasarkan tabel diatas dapat diartikan bahwa variabel kepuasan kerja berpengaruh positif terhadap variabel komitmen sebesar 7.155 dengan tingkat signifikan sebesar 0.000 yang lebih kecil dari 0.5. dengan persamaan sebagai berikut:

$$
\begin{aligned}
& \mathrm{Y} 1=\alpha+\beta 1 \mathrm{X}+\mathrm{e} 1 \\
& \begin{aligned}
\mathrm{Y} 1=2.198+0.467 \mathrm{X} & +\mathrm{e} 1 \\
\text { Error Term }(\mathrm{e} 1) & =\sqrt{ } 1-R^{2} \\
& =\sqrt{ } 1-0,213 \\
& =\sqrt{ } 0,787 \\
& =0,887
\end{aligned}
\end{aligned}
$$

Summary dan Koefisien Jalur II

\begin{tabular}{|l|l|l|l|}
\hline Variabel & $\begin{array}{l}\text { Koefesien } \\
\text { Reliabilitas }\end{array}$ & $\mathrm{T}_{\text {Hitung }}$ & Sig \\
\hline $\begin{array}{l}\text { Kepuasan } \\
\text { kerja }\end{array}$ & 0.453 & 9.866 & 0.000 \\
\hline Komitmen & 0.522 & 11.371 & 0.000 \\
\hline $\begin{array}{l}\text { Constanta } \\
\begin{array}{l}\text { Koefesien Determinasi } \\
\left(\mathrm{R}^{2}\right)\end{array} \\
\mathrm{F}_{\text {Hitung }}\end{array}$ & 0.410 \\
$\alpha$ & 211.755 \\
\hline \multicolumn{2}{|c|}{0.205} \\
\hline
\end{tabular}

diartikan bahwa variabel kepuasan kerja berpengaruh positif terhadap variabel Organizational Citizenship Behavior (OCB) sebesar 9.866 dengan tingkat signifikan sebesar $0.000<0.5 \%$. dan variabel kominmen berpengaruh positif terhadap variabel Organizational Citizenship Behavior (OCB) sebesar 11.371, dengan tingkat signifikan $0.000<$ $0,5 \%$ dengan persamaan sebagai berikut:

$$
\begin{aligned}
& \mathrm{Y} 1=\alpha+\beta 1 \mathrm{X} 1+\beta 2 \mathrm{X} 2+\mathrm{e} 1 \\
& \mathrm{Y} 1=0.410+0.453 \mathrm{X} 1+0.522 \mathrm{X} 2+\mathrm{e} 1 \\
& \text { Error Term }(\mathrm{e} 1) \quad \\
& \quad=\sqrt{ } 1-R^{2} \\
& =\sqrt{ } 1-0,698 \\
& =\sqrt{ } 0,302 \\
& \\
& =0,549
\end{aligned}
$$

Berdasarkan Summary dan Koefisein jalur 1 dan 2 maka dapat diketahui besarnya 
pengaruh langsung, pengaruh tidak langsung dan pengaruh total antar variabel. Perhitungan pengaruh antar variabel adalah sebagai berikut.

\section{Pengaruh Langsung}

a. Pengaruh langsung variable kepuasan kerja terhadap variabel komitmen dapat dilihat dari nilai beta atau standardized coefficient adalah $\mathrm{X} \rightarrow \mathrm{Y} 1=\mathrm{p} 1=0,467$

b. Pengaruh langsung variabel kepuasan kerja terhadap variabel Organizational Citizenship Behavior (OCB) dapat dilihat dari nilai beta atau standardized coefficient adalah $\mathrm{X} \rightarrow \mathrm{Y} 2=\mathrm{p} 2=0.453$

c. Pengaruh langsung variabel komitmen terhadap variabel Organizational Citizenship Behavior (OCB)dapat dilihat dari nilai beta atau standardized coefficient adalah

$\mathrm{Y} 1 \rightarrow \mathrm{Y} 2=\mathrm{p} 3=0.522$

\section{Pengaruh Tidak Langsung}

Pengaruh variabel kepuasan kerja terhadap variabe Organizational Citizenship Behavior (OCB) melalui variabel komitmen dapat diperoleh dengan menggunakan rumus sebagai berikut.

$$
\begin{aligned}
\mathrm{X} \rightarrow \mathrm{Y} 1 \rightarrow \mathrm{Y} 2 & =(\mathrm{p} 1 \times \mathrm{p} 3) \\
& =(0,467 \times 0.522) \\
& =0.243
\end{aligned}
$$

Nilai sebesar 0.243 memiliki arti bahwa Pengaruh variabel kepuasan kerja terhadap variabe Organizational Citizenship Behavior (OCB) melalui variabel komitmen adalah sebesar 0.243 atau 24.3 persen.

\section{Pengaruh Total}

Pengaruh total diperoleh dari hasil perhitungan dengan menggunakan rumus berikut.

Total Effect $=$ pengaruh langsung + pengaruh tidak langsung

$$
\begin{aligned}
& =\mathrm{p} 2+(\mathrm{p} 1 \times \mathrm{p} 3) \\
& =0.453+(0,467 \times 0.522) \\
& =0.453+0.243 \\
& =0.696
\end{aligned}
$$

Nilai sebesar 0.696 memiliki arti bahwa Pengaruh variabel kepuasan kerja terhadap variabe Organizational Citizenship Behavior (OCB) melalui variabel komitmen adalah sebesar 0.696 atau 69.6 persen.

Hasil Koefisien Detereminasi total

$$
\begin{aligned}
& \text { R2 } m=1-(\mathrm{e} 1)^{2}(\mathrm{e} 2)^{2} \\
& \text { R2 } \mathrm{m}=1-(0,887)^{2}(0,549)^{2} \\
& \text { R2 } \mathrm{m}=0,762
\end{aligned}
$$

Berdasarkan hasil perhitungan rumus koefisien determinasi total maka diperoleh bahwa keragaman data yang didapat dijelaskan oleh model adalah sebessar 0.762 atau 76.2 persen atau dengan kata lain informasi yang terkandung dalam data sebesar 76.2 persen dapat dijelaskan oleh model, sedangkan sisanya yaitu 23.8 persen dijelaskan oleh variabel lain (tidak terdapat dalam model) dan error.

Validasi Model Gambar Jalur Akhir

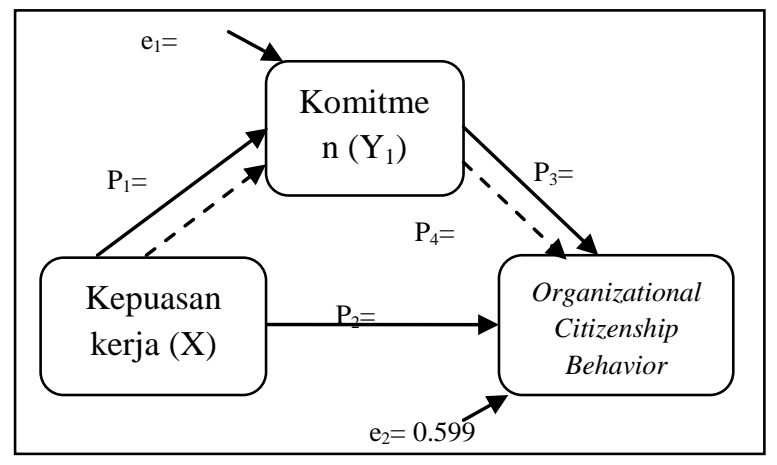




\section{HASIL DAN PEMBAHASAN}

\section{Pengaruh Variabel Kepuasan Kerja} Terhadap Variabel Komitmen

Hasil penelitian ini telah membuktikan bahwa variabel kepuasan kerja berpengaruh signifikan terhadap komitmen organisasi pegawai PT. Citayasah Perdana Hal ini ditunjukkan dari hasil statistik, yang menjelaskan besarnya koefisien estimase variabel kepuasan kerja terhadap komitmen organisasiadalah sebesar 7.155 (Sig. $=0,000$ Signifikan). Artinya jika variabel kepuasan kerja berubah (meningkat) ke arah yang lebih positif' 1 tingkatan maka komitmen organisasi pegawai PT. Citayasah Perdana juga akan meningkat sebesar 7.155. Komitmen organisasi memang sangatlah di perlukan dalam sebuah organisasi manapun.

Sebab dengan adanya komitmen yang tinggi maka visi misi perusahaan akan tercapai. Dengan meningkatkan kepuasan kerja yang berdampak pada meningkatnya komitmen, maka PT. Citayasah Perdana harus konsisten dalam menjaga tingkat kepuasa kerja pegawai. Kepuasan pegawai bukan hanya di ukur dari berapa gaji atau bonus yang di dapat. Melainkan banyak hal sebagai indikator kepuasan kerja, pegawai bisa merasa sebagai diri sendiri dalam menjalakan tugas juga merupakan kepuasan kerja. Sebab dengan merasan diri sendiri dan di beri kewenangan penuh dalam menjalakan tugas pegawai akan bisa berinovasi dalam melaksanakan tugas tersebut.

Dengan beban dan tanggung jawab yang diberikan PT. Citayasah Perdana dalam meningkatkan pelayanan ke masyarakat, yang dituntut tanpa padam dan percepatan dalam perbaikan gangguan. Maka pegawai harus bisa berinovasi agar gangguan-gangguan yang ada segera cepat teratasi. Dsamping itu lingkungan kerja yang harmonis juga merupakan penunjang kepuasan kerja, sebab dengan lingkungan kerja yang sehat maka merasa dalam keluaraga sendiri dan beban kerja terasa ringan.

Pengaruh Variabel Kepuasan Kerja Terhadap Variabel Organizational

\section{Citizenship Behavior (OCB)}

Hasil penelitian ini telah membuktikan bahwa variabel kepuasan kerja berpengaruh signifikan terhadap Organizational Citizenship Behavior (OCB) pegawai PT. Citayasah Perdana Hal ini ditunjukkan dari hasil statistik, yang menjelaskan besarnya koefisien estimase variabel kepuasan kerja terhadap komitmen organisasiadalah sebesar 9.866 (Sig.= 0,000 Signifikan). Artinya jika variabel kepuasan kerja berubah (meningkat) ke arah yang lebih positif' 1 tingkatan maka komitmen organisasi pegawai PT. Citayasah Perdana juga akan meningkat sebesar 9.866. Tidaklah mudah bagi perusahaan untuk meningkatkan

Organizational Citizenship Behavior


(OCB), sebab bagi pegawai merupakan suatu pekerjaan yang dianggap buang tenaga karena mereka lebih memilih menyelesaikan pekerjaan dimana sudah menjadi tanggung jawabnya saja. Akan tetapi dalam lingkungan kerja, dalam hal ini PT. Citayasah Perdana Organizational Citizenship Behavior (OCB) merupak suatu keharusan. Sebab demi kelancaran pendistribusian listrik dituntuk untuk percepatan dalam menangani gangguan aliran listrik pada pelenganggan. Sautu hal yang mustahil jika hal itu terjadi, sebab gangguan pada jaringan selalu datang kapanpun, baik dikarenakan gangguan internal maupun eksternal. Bila terjadi gangguan maka pegawai harus bertindak cepat untuk memperbaiki gangguan tersebut. Dengan adanya Organizational Citizenship Behavior (OCB) yang tinggih maa gangguan tersebut segara dan lebih cepat teratasi.

\section{Pengaruh Variabel Komitmen Terhadap Organizational Citizenship Behavior (OCB)}

Hasil penelitian ini telah membuktikan bahwa variabel komitmen berpengaruh signifikan terhadap Organizational Citizenship Behavior (OCB) pegawai PT. Citayasah Perdana. Hal ini ditunjukkan dari hasil statistik, yang menjelaskan besarnya koefisien estimase variabel kepuasan kerja terhadap komitmen organisasiadalah sebesar 11.137 (Sig.= 0,000 Signifikan). Artinya jika variabel kepuasan kerja berubah (meningkat) ke arah yang lebih positif' 1 tingkatan maka komitmen organisasi pegawai PT. Citayasah Perdana juga akan meningkat sebesar 11.137. . dengan demikian PT. Citayasah Perdana harus bisa meningatkan komitmen terhadap pegawai agar komitmen organisasi dalam hal ini PT. Citayasah Perdana bisa tercapai untuk meningkatkan kualitas pelayanan gangguan listrik dengan keomitmen " cepat dan tepat " segara terwujud dan tercapai sesuai dengan yang diharapkan. Sebab dengan meningkatnya Organizational Citizenship Behavior (OCB) gangguan antar rayon bisa cepat teratasi, sehinggah padamnya listrik karean gangguan tidak terlalu lama dan sesuai dengan ketentuan. Lamanya gangguan antar rayon disebabkan karena kurangangya tingkat kepedulian masing masing pegawai untk membantu pegawai yang lain dalam mengatasi gangguan.

\section{Pengaruh Variabel Kepuasan Kerja} Terhadap Organizational Citizenship Behavior (OCB) melalui Variabel

\section{Komitmen}

Hasil penelitian ini telah membuktikan bahwa variabel kepuasan kerja berpengaruh signifikan terhadap Organizational Citizenship Behavior (OCB) melalui variabel komitmen pegawai PT. Citayasah Perdana. Hal ini ditunjukkan dari hasil statistik, yang menjelaskan besarnya koefisien estimase variabel kepuasan kerja terhadap kinerja 
pegawaimelalui OCB dengan pengaruh langsung (direct effect) adalah sebesar 0.467 dan pengaruh tidak langsung (inderect effect) sebasar 0.243 dengan Itotal effect sebesar 0.696. Peningkatan Organizational Citizenship Behavior (OCB) pada pegawai PT. Citayasah Perdana. yang cukup besar diharapkan lebih cepat dan tepat dalam memberikan pelayanan gangguan pada waktu pendistribusian listrik.

\section{KESIMPULAN}

Berdasarkan pada hasil pengujian hipotesis penelitian dan pembahasan yang telah dilakukan di atas, maka dapat disampaikan simpulan hasil disertasi ini sebagai berikut :

1. Kepuasan kerja berpengaruh positif dan signifikan terhadap komitmen pegawai PLN Distribusi Jawa Timur Unit Pelayanan Mojokerto, dapat diartikan apabila kepuasan ditingkatkan maka komitmen pada pegawai akan semakin meningkat.

2. Kepuasan kerja berpengaruh positif dan signifikan terhadap Organizational CitizenshipBehavior (OCB) pegawai PT. Citayasah Perdana, dapat di artikan apabila kepuasan ditingkatkan maka Organizational CitizenshipBehavior (OCB) pada pegawai akan semakin meningkat.

3. Komitmen organisasi berpengaruh positif dan signifikan terhadap
Organizational CitizenshipBehavior

(OCB) pegawai PT. Citayasah Perdana, dapat diartikan apabila komitmen semakin ditingkatkan maka Organizational CitizenshipBehavior (OCB) pada pegawai akan semakin meningkat.

4. Kepuasan kerja berpengaruh signifikan terhadap Organizational Citizenship Behavior (OCB) melalui komitmen pegawai PT. Citayasah Perdana, dapat diartikan bahwa kepuasan kerja yang meningkat maka akan di ikuti pula peningkatan pada komitmen organisasi, sehinggah Organizational Citizenship Behavior (OCB) juga akan meningkat yang disebabkan oleh terjalinnya kerja sama dan kebersamaan yang bagus.

\section{DAFTAR PUSTAKA}

Allen N.J and Meyer J.P. 1990. "Measurem ent of Antecendents of Affective, Continuance and Normative Commitment to Organizational" Journal of Occupational Psychology: Hal. 63:1-8.

Algifari. 2000. Analisis Regresi : Teori, Kasus dan solusi, Yogyakarta: BPFE.

Artanti. 2002. "Pengaruh Perilaku Kepemimpinan Transaksional dan Transformasional terhadap OCB dengan Pemberdayaan Psikologis dan Substitute Kepemimpinan Sebagai Variabel Pemoderasi” (Tesis). Yogyakarta: UGM.

As'ad M. 1995. Psikologi Industri. Yogyakarta: Libert

Arbuckle, J.L. 1994. “Analysis of Moment Structure Psychometrica" AMOS 59, 135-137.

David A. Foote. 2008. "Job satisfaction and organizational citizenship behavior 
(OCB)" International Journal of Business, Vol. 27 No. 4; hal. 78-91.

Davis, Keith. 1996. Perilaku dalam organisasi. Jakarta : Erlangga.

Djarwanto. 2003. Mengenal Beberapa Uji Statistik dalam Penelitian, Yogyakarta : Liberty.

Dumler, Michael P.\& Schanke, Mel. 1997. "Organizational Citizenship Behavior : The Impact of Rewards And Rewards Practices" Journal of Managerial Issues, Vol.IX Number 2 Summer.

Dunham. 2000. "Organizational Commitment : The Utility of an Integriate Definition" Journal of Applied Psychology, Edisi 79.

Dyne, L.Van. 2001. "Organizational Citizenship Behavior: Construct Redefinition,Measurement, and Validation" Academy Of Management Journal, Vol. 37, No.4, Hal.765-802.

Debora Eflina.P. 2004. "Pengaruh kepribadian dan komitmen organisasi terhadap Organizational citizenship behavior (OCB)" Journal, Vol. 8 No. 3; hal. 10-23.

Ferdinand, Augusty. 2002. Structural

Equation Modelling dalam Penelitian Manajemen Semarang: FE UNDIP.

Fatema, Mohammed. 2013. "Job Satisfaction and Organizational Commitment: A Correlational Study in Bahrain" International Journal of Business, Humanities and Technology, Vol.3 No.5. Hal 134-141.

Gibson, James L., Ivancevich, Jhon M., Donnely, Jr., James H. 1994. Organisasi Dan Manajemen, Jakarta : Penerbit Erlangga.

Ghozali, Imam. dan Fuad. 2005. Structural Equation Modeling: Teori, Konsep, dan Aplikasi dengan Program Lisrel 8.54 Semarang: Badan Penerbit-Undip.

Ivanchevich, John M. 1993. Organizational Behavior And Management, , Newyork : Irwin McGraw-Hill, Fifth Edition.

Kuehn, Kermit W. dan Yousef Al-Busaidi. 2002. "Citizenship Behavior In-non Western Context : An Examination of
The Roof Satisfaction, Commitment and Job Characteristic On SelfReported OCB" IJCM Vol. 12, No 2, Hal.23-34.

Linda. T. 2013. "Organization Citizenship Behavior (OCB) Dan Komitmen Organisasi Pengaruhnya Terhadap Kinerja Karyawan Di PT. Bank Tabungan Pensiunan Nasional (BTPN) Cabang Utama Manado" Journal EMBA, Vol.1 No.4.Hal. 110126.

Luthans, F. 1995. Organizational Behavior: New York : Mc Graw Hill.

Luthans, F. 2006. Perilaku Organisasi. Edisi Pertama. Yogyakarta:Penerbit Andi.

Mc Shane, Steven L. \& Mary Ann Von Glinow. 1995. Organizational Behavior, New York : Mc Graw Hill.

Meyer , J.P. \& Allen, N.J. 1990. "The Measurement and Antecedent of Affective, Continuance, and Normative Commitment to the Organization" Journal Of Occupational Psychology, Vol.63, hal.1-18.

Moorman, R.H. 1990. "Relational Between Organizational Justice and Organizational Citizenship Behavior : Do Fairness Perceptions Influence Employee Citizenship?" Journal of Applied Psychology, Vol. 76, No.6, Page 845-855.

Morrison, Elizabeth Wolfe. 1994. "Role Definitions and Organizational Citizenship Behavior : The Importance of The Employe's Perspective" Academy of Management Journal, Vol.37, No.6, hal.1543-1567.

Muhid, Abdul. 2008. Modul Analisis Data Statistik Parametrik dan Non Parametrik program SPSS. Surabaya : Psikologi IAIN.

Podsakof. 2001. "Transformational Leader Behaviors and Substitutes for Leadership as Determinant of Employee Satisfaction, Commitment, Trust, and Organizational Citizenship Behavior" Journal of Management, Vol.22, No.22, hal, 259-298. 
Purnama.C. 2013. "Influence Analysis of Organizational Culture Organizational Commitment Job and Satisfaction Organizational Citizenship Behavior (OCB) Toward Improved Organizational Performance" International Journal of Business, Humanities and Technology, Vol. 3 No. 5; hal. 12-35.

Robbins, S. P. 2002. Perilaku Organisasi, Jilid I, Edisi 9 (Indonesia). Jakarta: Gramedia.

Robbins, S. P.1996. Prinsip-Prinsip Perilaku Organisasi. Jakarta: Erlangga.

Robbins, S. P. 2003. Perilaku Organisasi. Jakarta: Gramedia.

Robbins, S.P. 2008. Organizational Behaviour. Jakarta : Salemba Empat.

Robbins, S.P. 2003. Organizational Behaviour. Jakarta: Macanan Jaya Cemerlang.

1996. Perilaku

Organisasi. Jakarta : Prenhallind. . 2002. Prinsip - Prinsip

Perilaku Organisasi. Jakarta: Erlangga.

Saimir. 2013. "Job Satisfaction And Organizational Commitment: The Case Of Shkodra Municipality" European Scientific Journal, vol.9, No.17. Hal.126-142.

Sedarmayanti dan Syarifuddin Hidayat. 2002. Metodologi Penelitian, Bandung: Mandar Maju.

Strauss, George dan Leonard Sayles. 1996. Manajemen Personalia, Segi Manusia Dalam Organisasi. Jakarta : Pustaka Binaman Pressindo.

Sugiyono. 2009. Metode Penelitian Kuantitatif, Kualitatif dan $R \& D$. Bandung : Alvabeta.

Sugiyono. 2006. Statistika Untuk Penelitian. Bandung: CV. Alfabeta.

Suharjo, Bambang. 2008. Analisis Regresi Terapan dengan SPSS. Yogyakarta :Graha Ilmu.

Supranto, J. 1998. Teknik Sampling. Jakarta : Rineka Cipta.

Suryabrata, Sumadi. 1996. Metode Penelitian, Jakarta: Rineka Cipta.
Thaha, Miftah. 1998. Perilaku Organisasi Konsep Dasar dan Aplikasinya. Jakarta: Raja Grafindo Persada.

Utomo, Kabul Wahyu. 2001. "Kecenderungan Kepemimpinan Transaksional dan transformasional dan hubungannya dengan OCB, Komitmen dan Kepuasan Kerja" (Tesis) Yogyakarta: UGM.

Wahyuni, Erni Endah. 2006. "Kontribusi Zuhud dan Emotional Intelligence terhadap OCB bagi karyawan RSU Bhakti Asih, Karang Tengah, Tangerang Banten" (Tesis). Depok: Universitas Indonesia.

Wexley, Kenneth N., Garry Yulk. 1992. Perilaku Organisasi dan Psikologi Personalia. Jakarta: Rineka Cipta. 